Conclusions. The development of patriotic education of students by means of vocal works in the People's Republic of China is manifested in the following main directions:

- patriotic education acquires a continuous interdisciplinary character, filling all types of educational work with patriotic content;

- educational work is not limited to school music and singing lessons, but takes place in the process of preparing children to participate in various modern musical projects (children's opera, children's musical, children's TV shows, laser shows, open-air performances, installations, etc.), as well as with the direct participation of children in these projects;

- the new information environment and media technologies allow us to expand the possibilities for the implementation of the functions of vocal art (communicative, propaganda, aesthetic, cognitive, educational);

- in connection with the changes in the social, economic and cultural spheres of society, vocal art undergoes noticeable changes under the influence of the intensive development of art in general (the emergence of new styles and trends, the mutual influence of different genres (song, dance, portrait, landscape, etc.) and types of art (literature, painting, music, theater, etc.).

- the school song, being developed in various projects with the help of modern technologies, reveals the images of the characters in a new way due to the predominance of peaceful, rather than military themes (among the patriotic themes there are songs about the Motherland, the nature of the native land, the family, work for the good of the country, but there are almost no songs about war).

$$
* * *
$$

1. Wang Yu. The history of Chinese song. Beijing: Publishing house "Folk Music", 2012. 367 p.

2. Zhao Chunlei. Evolution of the style of writing patriotic songs in the new era // Musical Creativity. 2019. No. 8. P. 106-112.

3. Go Ying. On the education of patriotism in musical evaluation // Information about Science and Technology. 2016. No. 29. P. 127-129.

4. Liu Liping. Film and television // Music and Patriotism. 2007. No. 14. P. 65.

5. Yu Zhong, Wang Jie. Discussion of Li Shutun's creativity-patriotic feelings in school songs // Art Education. 2019. No. 12. P. 58-60.

6. Yang Yuchen. Teaching music and education of patriotism // Chinese Music Education. 2018. No. 1. P. 44-46.

7. Chen Yulin. Love music, love the Motherland-how to develop students' patriotism in music teaching // Northern Music. 2018. No. 16. P. 32-41.

8. Chen Haochun. Education of patriotic qualities in primary school students // Education in Gansu. 2014. No. 20. P. 115-118.

9. Zhong Zhenglin. Listen to the song of China // Shikan Magazine. 2017. No. 17. P. 15-16.

\title{
Fu Ying \\ Pedagogical potential of visual activities in environmental education of students in China
}

Beijing University (China, Beijing)

doi: $10.18411 /$ sr-10-04-2021-70

\section{Abstract}

Our research identifies the role of visual activities in the environmental education of schoolchildren, so the goal of this article is to analyze the concepts of modern Chinese scientists who are directly related to this problem.

Key words: visual activities, environmental education, ecological culture, cultural values, ecological thinking. 
In early childhood, in the process of family education, the child receives the first knowledge about the surrounding nature, which is subsequently replenished and consolidated in preschool and secondary school. According to Chinese teachers (Ma Qiang, Zhang Jing), the role of the adult in the formation of the correct relationship between the child and nature is extremely great, since under the influence of the educator, the child begins to treat nature as a common value for all mankind [1]. Continuing the ideas of outstanding Chinese thinkers of the past about the relationship between man, society and nature, modern researchers also see in nature a powerful source of comprehensive growth of the younger person in terms of the development of his moral, patriotic, strong-willed qualities, aesthetic and emotional-sensory perception, artistic taste, etc. [2].

First of all, let's consider the approaches of Chinese researchers to the definition of the concept of "visual activity".

Visual activity, according to a number of scientists (Guo Jiwei, Wang Shengzhen), is multi-valued in terms of connection with reality, as well as multifunctional in terms of its manifestation [3]. Engaging in visual activities leads to the creation of an artistic image and the actual work as a material expression of the image. At the same time, the image, as Guo Jiwei emphasizes, does not just copy the object, but embodies the thoughts, emotions and experiences of the author. The emotions and experiences of the author give rise to a plan, which the author begins to translate gradually into an image, and then implement it in a work of art using the means of visual art [Ibid.].

Zhang I connects visual activity with the student's solution of a visual problem through various artistic materials (or means of expression). For a child, visual activity is always associated with the joy of learning and creativity, so the scientist refers it to the main means of aesthetic education of students. Among the types of visual activities in high school, the author refers to painting, graphics and modeling. In painting lessons, children try to solve pictorial problems with the help of color and its combinations, which in this case is the leading means of expression. Children learn to associate colors with different feelings and moods - joy, sadness, tenderness, anxiety, etc. When drawing, children learn to draw objects on a plane or to solve a visual problem using expressive means of graphics - lines, strokes, contours, tones. The oldest type of graphic art is drawing. While modeling, children learn to convey images of people, living and inanimate nature with the help of plastic materials that allow you to change the shape many times before achieving the desired result. It is modeling classes that help to form the child's ability to give the greatest expressiveness to the intended image (character, mood, age, movements of the hero, etc.) [4]. As the author emphasizes, each of these types of visual activity should be present at school classes for a comprehensive approach to solving educational problems of an aesthetic, environmental and moral nature.

It should be noted that one of the goals of the school subject "Fine Arts" is associated by the authors of the curriculum with the formation of the ecological culture of students. Thus, the author's team under the leadership of Lo Kunlun points to the need to educate the ecological and aesthetic culture of students based on a deep interest in the visual arts, respect and love for national culture and native nature as the cultural heritage of the people, readiness and ability to protect and increase the national cultural wealth [5].

Chen Xiaohong defines the purpose of the discipline "Fine Arts" as the formation of students' ecological culture as an important component of artistic and aesthetic culture, based on the highest cultural values of civilization [6].

In the course of any type of educational activity, including visual activities, the student learns certain knowledge, as well as develops sustainable skills of applying the learned material. Chinese teachers believe that the knowledge of an ecological nature acquired in the course of classes is more solid, and lays the foundation for the formation of environmental consciousness of students. The personal significance of the educational material and the emotional attitude of the student to the studied material affect the degree of its assimilation by the student. Therefore, according to Chinese teachers, in order to create psychological 
prerequisites for lasting assimilation, the educational material should not only be new for the student, but also arouse his interest, positive emotions, joy, and pleasure from work. Since visual activity is associated with the direct activity of the student, any kind of visual activity can be an effective means to supplement the environmental knowledge of students. Dou Aihua recommends that the teacher rely on two main components of the process of mastering the educational material of environmental content. First, the initial perception of the material by the student plays a decisive role, since, comprehending the information, he forms a certain attitude to it. The second component is related to the personal conditionality of assimilation, when the student evaluates the material for personal significance. Both components of the learning process contribute to or hinder the formation of the student's motivation to further study the subject [7].

Environmental education, according to Huang Jialing, cannot be narrowly focused because of the multidimensional nature of the problem of the relationship between man, nature and society, which affects all spheres of human activity in society. This, according to the author, makes it possible to link the goal of environmental education for the formation of ecological thinking of schoolchildren with traditional areas of educational work, considering that the leading direction in drawing lessons will be aesthetic education. The author emphasizes that the close interweaving of ecological and aesthetic perception of nature, based on the general principle of natural harmony, will allow to realize the goal of ecological education through visual activities in the classroom, since the aesthetic perception of nature with the subsequent image of beautiful images encourages the child to think about the need for careful attitude to the surrounding beauty [8].

The close connection between the goals of environmental and aesthetic education in the drawing lesson is also indicated by a group of researchers led by Tang Juan. Since the ecological crisis on the planet can lead to an aesthetic crisis, i.e. to the disappearance of natural beauty and the loss of objects of inspiration for the creation of new objects of art by humanity, it is necessary to educate the ecological and aesthetic consciousness of schoolchildren in order to understand the ecological component of art and the attitude to nature as an important component of the culture of the entire nation [9].

We should also pay attention to the concept of ecological education by Ma Qiang, in which the author connects the ecological, aesthetic and moral directions of the teacher's work, calling them complementary [10]. According to the author, the threat of an ecological catastrophe and the loss of a person's ability to receive aesthetic pleasure from communicating with nature should become a moral imperative in human behavior in relation to nature. These areas of educational work in different ways, complementing each other, affect the student. Moral behavior in relation to nature consists in the desire to follow universal moral principles in relation to the surrounding living and inanimate nature, a sense of duty, responsibility to oneself and other people. Ecological behavior is expressed in the willingness to protect nature, to use its resources rationally, and aesthetic behavior is associated with the ability to understand and appreciate the beauty of nature and the need to create beauty for the benefit of humanity.

The educational potential of fine arts classes is addressed in Ma Xin studies [11]. The author focuses on the developing potential of visual activity. He believes that the lessons of fine arts not only support the interest of students in different types of art, but also help to preserve and develop the cognitive interest of students in general. In other words, the student will be able to approach any type of educational activity creatively, if it arouses his interest, awakens his imagination.

Conclusion. The concepts discussed above allow us to conclude that Chinese teachers carry out environmental education in fine art classes through visual activities through value and activity approaches to learning, which contribute to the formation of motivation for learning, a creative approach to any type of activity in the classroom, enrich students' 
environmental knowledge, develop imagination and aesthetic taste, awaken the desire to learn about the world, understand the importance of preserving nature for human life and creating art objects. In general, visual activity, as one of the types of educational activity, helps students to form the necessary algorithms of actions to solve the educational problem by means of visual activity, strengthens visual skills, and also leads to the creation of personal meanings regarding the depicted objects.

1. Ma Qiang, Zhang Jing. The implementation of ecological civilization education // Environmental education. 2020. No. 8. P. 62-65.

2. Li Zhixin. The ecosystem of "full learning" for the comprehensive development of students // Guide to Environmental Research. 2019. No. 5. P. 26-27.

3. Guo Jiwei, Wang Shengzhen. Education of environmental responsibility in secondary school students // Guide to environmental Research. 2020. No. 23. P. 25-28.

4. Zhang I. Analysis of the children's play environment in the framework of the ecological concept // Talent. 2019. No. 7. P. 16-18.

5. Lo Kunlun, Jan Tensho. Reconstruction of the harmonious relationship between man and nature from the point of view of ecological civilization // Journal of ecology. 2020. No. 2. P. 1-7.

6. Chen Xiaohong. Development of courses of complex practical activity on the topic "Ecological situation in the Yangtze River area" // Science in primary School. 2020. No. 3. P. 13-14.

7. Dou Aihua. Theoretical thinking and practical strategies for environmental education // The world of primary school children. 2019. No. 2. P. 7-12.

8. Huang Jialing. The penetration of ecological morality into the teaching of the Chinese language in primary school // Handbook for primary school. 2019. No. 4. P. 95.

9. Tang Juan. Ecological education penetrates into the practice of teaching the Chinese language // Manual for primary school. 2019 No. 18. P. 29-30.

10. Ma Qiang, Zhang Jing. The implementation of ecological civilization education // Environmental education. 2020. No. 8. P. 62-65.

11. Ma Xin. Legislation on eco-education in the People's Republic of China // Law and State. 2017. No. 10 (154). P. 83-89. 